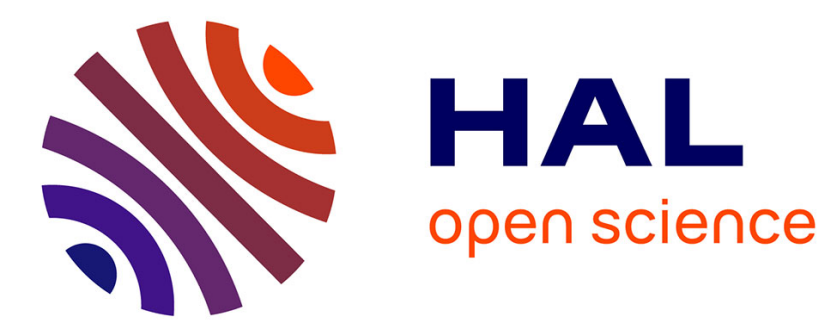

\title{
Soft X-Ray Absorption Spectroscopy with Variable Surface Sensitivity using Fluorescence Yield Detection
}

\author{
Y. Kitajima
}

\section{To cite this version:}

Y. Kitajima. Soft X-Ray Absorption Spectroscopy with Variable Surface Sensitivity using Fluorescence Yield Detection. Journal de Physique IV Proceedings, 1997, 7 (C2), pp.C2-705-C2-706. 10.1051/jp4:1997212 . jpa-00255178

HAL Id: jpa-00255178

https://hal.science/jpa-00255178

Submitted on 1 Jan 1997

HAL is a multi-disciplinary open access archive for the deposit and dissemination of scientific research documents, whether they are published or not. The documents may come from teaching and research institutions in France or abroad, or from public or private research centers.
L'archive ouverte pluridisciplinaire HAL, est destinée au dépôt et à la diffusion de documents scientifiques de niveau recherche, publiés ou non, émanant des établissements d'enseignement et de recherche français ou étrangers, des laboratoires publics ou privés. 


\title{
Soft X-Ray Absorption Spectroscopy with Variable Surface Sensitivity using Fluorescence Yield Detection
}

\author{
Y. Kitajima
}

Photon Factory, National Laboratory for High Energy Physics, 1-1 Oho, Tsukuba, Ibaraki 305, Japan

\begin{abstract}
Surface sensitivity in the soft X-ray absorption spectroscopy by the fluorescent $X$-ray yield detection under grazing exit condition is discussed. It is experimentally demonstrated at $\mathrm{Si} K$-edge that the sampling depth can be controlled by changing exit angles in the vicinity of the critical angle for total reflection.
\end{abstract}

\section{INTRODUCTION}

For the XAFS measurements of bulk solid materials in the soft X-ray region, total electron yield (TEY) technique has been mostly employed but fluorescent X-ray yield (FY) detection has recently been proposed as an alternative $[1,2]$, where surface sensitivity is discussed considering the penetration depth of the emitted photons. On the other hand, it was shown in the hard $\mathrm{X}$-ray region that $F Y$ is applicable to surface probe if the observation angle is less than the critical angle $\left(\theta_{\mathrm{C}}\right)$ for total reflection [3]. This report aims to clarify experimentally how the surface sensitivity of FY varies under extreme grazing exit condition in the soft $\mathrm{X}$-ray region.

\section{EXPERIMENTAL SET-UP}

Figure 1 schematically illustrates the experimental set-up. A silicon wafer with $195 \AA$ thick surface oxide was chosen as a typical sample to evaluate surface sensitivity. Soft X-ray beams monochromatized with a pair of $\mathrm{InSb}(111)$ crystals at PFBL-11B [4] illuminate the sample at nearly normal incidence. Horizontal beam size was set to $3 \mathrm{~mm}$ by the incidence slit $\mathrm{S}_{1}$. Silicon $K \mathrm{FY}$ was monitored with a gas-flow proportional counter (PC) [5]. The sample was precisely rotatable with a stepping motor around the vertical axis so that the exit angle $\left(\theta_{\mathrm{E}}\right)$ of the fluorescent X-rays can be controlled. Observation angle spread of $P C$ was set to about $2.2 \mathrm{mrad}$ by the $0.5 \mathrm{~mm}$ opening exit slit $\mathrm{S}_{\mathrm{E}}$ at a distance of $220 \mathrm{~mm}$ from the incident beams. TEY was simultaneously recorded by the drain current from the sample with a picoammeter.

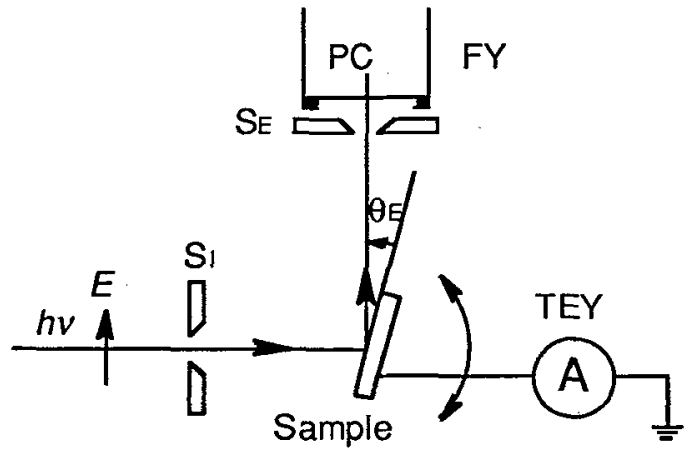

Figure 1: Schematic diagram showing the experimental set-up.

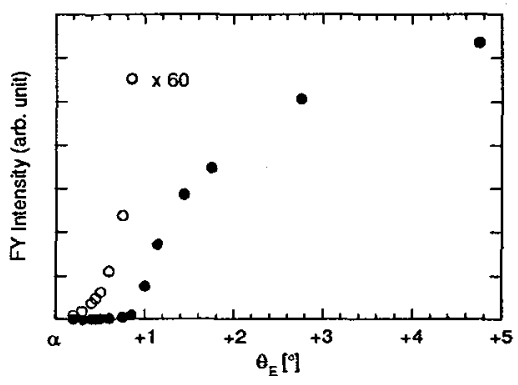

Figure 2: Exit angle dependence of FY intensity. 
Although it is hard to know the absolute value of $\theta_{\mathrm{E}}$ in the present experimental condition, it was estimated from the variation of FY intensity with rotating the sample. Figure 2 shows the $\theta_{\mathrm{E}}$ dependence of the FY intensity, where $\theta_{\mathrm{E}}$ is expressed relative to an unknown value of $\alpha$. By comparing this curve with the calculation $\left(\theta_{\mathrm{C}} \approx 0.9^{\circ}\right)$ and previous experiments for a Si wafer $[6], \alpha$ was estimated to be zero.

\section{RESULTS AND DISCUSSION}

Figure 3 shows the Si K-edge FY XANES spectra at various grazing exit angles. The first two peaks at $1842.5 \mathrm{eV}$ and $1848.5 \mathrm{eV}$ are well known as characteristic features of the bulk silicon and surface oxide, respectively. It is clearly seen that the intensity of the oxide peak does not follow the total FY intensity as the exit angle decreases. This indicates the sampling depth of FY changing with $\theta_{\mathrm{E}}$. In order to compare surface sensitivity between FY and TEY, these spectra were normalized by the edge jump (Fig. 4). It should be mentioned that the pre-edge background was subtracted for only the TEY spectrum. As expected, the surface sensitivity of FY changes drastically as $\theta_{\mathrm{E}}$ crosses the critical angle $\theta_{\mathrm{C}}$. It becomes higher than TEY under extreme GE condition $\left(\theta_{\mathrm{E}}<\theta_{\mathrm{C}}\right)$. In this sense, previous estimation of the information depth in Ref. [2] is insufficient. On the other hand, FY at a larger grazing exit angle is more bulk sensitive than TEY. Thus variable surface sensitivity is realized by this GE-FY detection method.

Extreme GE condition has some advantages as a surface probe compared to other previous methods such as "Total Reflection" (TR) method and Auger Electron Yield (AEY) detection. It is inevitable to correct anomalous absorption effects in TR method and surface sensitivity cannot be adjusted because the kinetic energy as well as the escape depth of the Auger electrons are specified for elements.

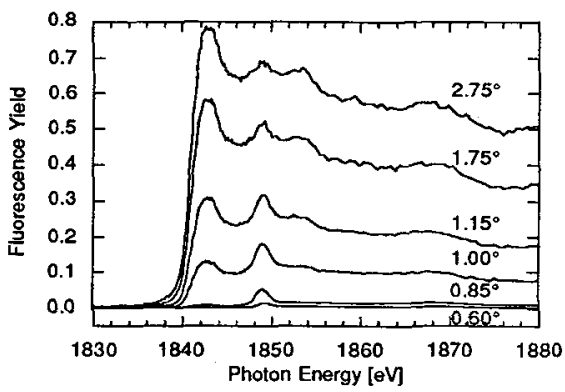

Figure 3: Si K-edge FY XANES spectra at GE condition.

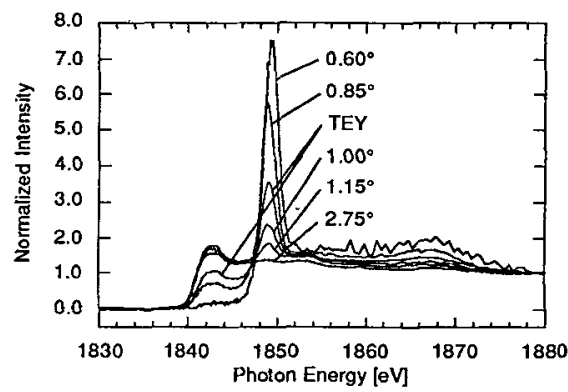

Figure 4: Normalized XANES spectra by FY and TEY.

It is well demonstrated that the FY detection can be more and less surface sensitive than TEY by slightly changing the grazing exit angle around the critical angle for total reflection. This controllability of surface sensitivity is quite useful in XAFS study for both the surface and bulk properties as well as depth-profile analysis.

\section{Acknowledgments}

The present author is grateful to Prof. A. Iida (PF, Tsukuba), Dr. J. Kawai (Kyoto Univ.), Dr. S. Hayakawa (The Univ. Tokyo) and Dr. S. Yasuami (Toshiba Co.) for valuable discussions. This work has been performed under the approval of the Photon Factory Program Advisory Committee (PF-PAC No. 95G377).

\section{References}

[1] Tröger L., Arvanitis D., Baberschke K., Michaelis H., Grimm U., Zschech E., Phys. Rev. B 46 (1992) 3283-3289.

[2] Kitajima Y., Rev. Sci. Instrum. 66 (1995) 1413-1415.

[3] Suzuki Y., Phys. Rev. B 39 (1989) 3393-3395.

[4] Kitajima Y., J. Elec. Spec. Relat. Phenom. 80 (1996) 405-408.

[5] Funabashi M., Ohta T., Yokoyama T., Kitajima Y. and Kuroda H., Rev. Sci. Instrum. 60 (1989) 2505-2508.

[6] de Bokx P.K. and Urbach H.P., Adv. X-Ray Chem. Anal. Jpn. 26 s (1995) 199-204. 